\title{
Subdural Haematoma in Infancy
}

\author{
PATRICIA A. RUSSELL,* M.B., B.S., M.R.C.P., D.c.H.
}

The unsuspected subdural haematoma of infancy remains a numerically small but significant cause of mental retardation and physical handicap. Ingraham and Matson (1944), in their now classical paper, stressed that this condition must be actively sought if cases are not to be missed. Statten (1948) commented that their paper had stimulated interest at the Hospital for Sick Children, Toronto, and, as a result, in the next 16 months an average of one case a month was diagnosed, whereas previously the average had been one case a year. The condition has received scant attention in the British literature apart from a report of 18 cases by Guthkelch (1953). During four years of study he found that of all surgical conditions of the central nervous system seen in the first two years of life only spina bifida and hydrocephalus were more common than subdural haematoma.

The purpose of this paper is to review 25 cases seen in the Children's Department of King's College Hospital and in the Guy's-Maudsley Neurosurgical Unit during the years 1953-63, with particular reference to the presenting features, and to assess the prognosis. Sixteen of these cases were seen initially at King's College Hospital in the ordinary run of a paediatric service. The 25 cases came from widely different sources, and although some of the cases referred to the Guy's-Maudsley Neurosurgical Unit had had previous subdural taps it did not seem likely that the taps were the cause of the bleeding.

\section{Case Material}

Age and Sex.-The 25 patients were all under the age of 2 years. Sixteen (64\%) presented in the first six months of life, six of these in the neonatal period (Table I). There were 15 males and 10 females.

\begin{tabular}{|c|c|c|c|c|}
\hline $\begin{array}{c}\text { Age } \\
\text { in Months }\end{array}$ & $\begin{array}{l}\text { No. of } \\
\text { Cases }\end{array}$ & $\underset{\text { Trauma }}{\text { Birth }}$ & $\begin{array}{c}\text { Post-natal } \\
\text { Trauma }\end{array}$ & $\begin{array}{l}\text { No History } \\
\text { of Trauma }\end{array}$ \\
\hline $\begin{array}{lll}\text { Less than } 1 & \ldots \\
1-5 & \ldots & \\
6-24 & \ldots & \end{array}$ & $\begin{array}{r}6 \\
10 \\
9\end{array}$ & $\begin{array}{l}3 \\
0 \\
1\end{array}$ & $\begin{array}{l}0 \\
6 \\
5\end{array}$ & $\begin{array}{l}3 \\
4 \\
3\end{array}$ \\
\hline Total & 25 & 4 & 11 & 10 \\
\hline
\end{tabular}

Aetiology.-Four cases had a definite history of a difficult birth. Eleven cases had a history of post-natal head injury. In eight of these a legitimate accident had occurred, in three it was thought that injury had been inflicted. Ten had no history of birth or post-natal trauma. One case had thrombocytopenic purpura. Nine children came from an unstable home background where the parents were separated, unmarried, or quarrelling. Of the three children who were probably subjected to violence, one had had a fractured nose at the age of 5 months, and on admission at 7 months she had a fractured right parietal bone and traumatic periostitis of the right humerus. The second had had a fractured tibia at the age of 2 months, and on admission at 5 months had severe bruising of the face and subconjunctival haemorrhage. The third, aged 8 months, was

* Senior Registrar, Children's Department, King's College Hospital, London. Now Lecturer, Institute
Hospital for Children. London. said to be "always falling out of her pram" and "her head had come into contact with her father's boot": on admission she was covered with bruises at all stages of resolution.

\section{Presenting Features}

Nineteen cases presented with a generalized convulsion, 14 were vomiting, and 11 were said to be drowsy (see Chart). Three children were retarded when they were first seen. In two of these, boys of 18 and 20 months, it was likely that the haematoma had been present since birth. The third child, a girl of 18 months, had spent most of her life in the care of foster mothers and no accurate history was available. Two children had failed to gain weight adequately.

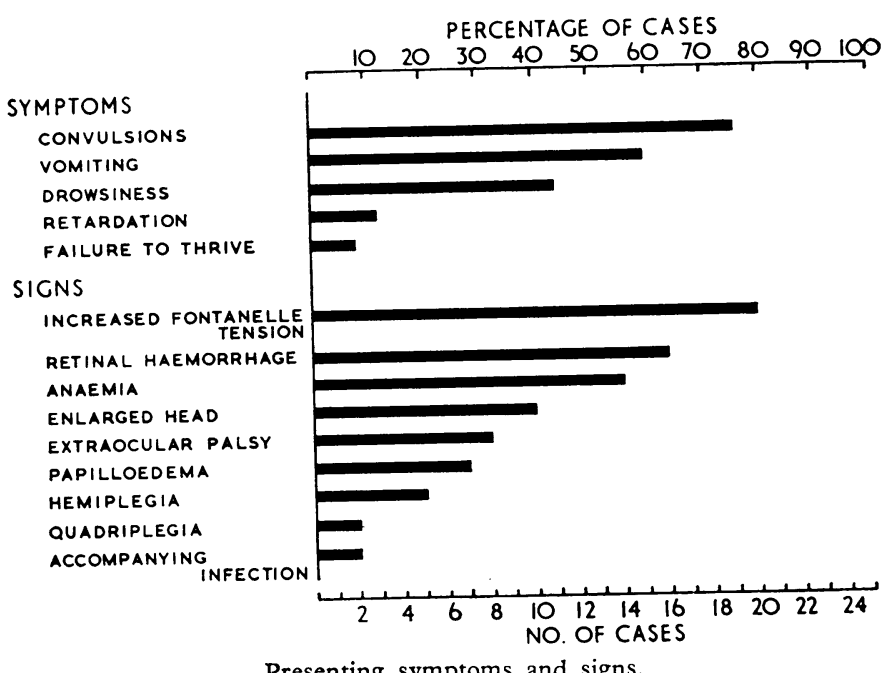

Presenting symptoms and signs.

The signs were increased tension of the anterior fontanelle in 20 cases, enlarged head in 10 , retinal haemorrhage in 16 , and seven of these also had papilloedema. One 18-month-old girl was underweight and retarded, but otherwise had no abnormal physical signs except for small bilateral retinal haemorrhages. Three cases had a unilateral sixth-nerve palsy, five had a unilateral third-nerve palsy involving pupil reaction and external ocular movement. Five infants showed a spastic hemiplegia - on the side of the haematoma in two, on the opposite side in two, and in one the haematoma was bilateral. Two children had a spastic quadriplegia with unilateral haematoma. Fourteen children had a significant anaemia for their age. One child had accompanying acute tonsillitis on admission and one had bronchopneumonia.

Four cases illustrated the acute presentation in the early neonatal period: two on the second day of life and two on the third appeared pale and shocked, with a lowered level of consciousness and periods of apnoea. Convulsions occurred in two and all had increased anterior fontanelle tension. Subdural needling with release of apparently pure blood improved these babies dramatically; they regained full consciousness and respirations became regular. 


\section{Treatment}

The diagnosis was confirmed in 20 cases by subdural needling through the coronal suture just lateral to the anterior fontanelle, and in the remaining five older children, in whom the fontanelle was closed, by exploration through burr-holes. Bilateral haematoma were present in 18 cases and unilateral in 7 . In three cases presenting in the neonatal period the subdural space became dry after a few needlings and no further treatment was given. In 22 cases the regime suggested by Ingraham and Matson (1944) was followed. The intracranial pressure was gradually reduced by repeated subdural needling, not more than $15-20 \mathrm{ml}$. of fluid being removed at any one puncture. An attempt to remove all the available fluid at one time may cause severe shock in an ill infant. If necessary anaemia was corrected by transfusion, and when the general condition was satisfactory exploration for residual clot and membranes was made through burr-holes. If these were present they were removed at craniotomy. In 20 cases residual clot or membrane was found on one or both sides. In three of the cases explored by craniotomy in the neonatal period extensive solid clot was found ; in one case this was $2 \mathrm{~cm}$. thick and extended from the frontal to the occipital pole.

In four exceptional cases the membrane could not be satisfactorily removed.

Case 1.-A 4-month-old male developed dermatitis of the scalp. Severe raised intracranial pressure made needling through the inflamed area unavoidable. A left subdural empyema due to Staphylococcus aureus infection developed. This responded to systemic and local instillation of chloramphenicol, but at subsequent craniotomy firm membrane 3-5 $\mathrm{mm}$. thick was found. In many parts this could not be separated from the cortex. At 11 months of age staphylococcal meningitis developed. Further exploration through a left frontal burr-hole showed tight fibrous meninges $1 \mathrm{~cm}$. thick with soft necrotic cortex beneath. At $2 \frac{1}{2}$ years he was severely retarded.

Case 2.-A 4-month-old male was admitted for investigation of convulsions which had started at the age of 2 months. On admission he was found to have idiopathic thrombocytopenic purpura-haemoglobin $19 \%$. After blood transfusion, decompression of the subdural spaces, and control of the thrombocytopenia with steroids craniotomies were performed. On the left side the membrane was $0.5 \mathrm{~cm}$. thick, and the underlying cortex was pale and shrunken. On the right side the membrane was $2 \mathrm{~cm}$. thick and only a disk $5 \mathrm{~cm}$. in diameter could be removed. At 18 months of age he was severely retarded mentally and physically. It is of interest that he had been seen at another hospital when aged $2 \frac{1}{2}$ months and a bruit had been heard over the right frontal area. Lumbar puncture and right carotid angiography at that time were considered normal and the subdural space was not needled. Grunnagle (1949) reported a case where the bruit disappeared after subdural tap.

Case 3.-A third male child was seen aged 20 months. He had had a difficult forceps delivery and needed strenuous resuscitation. From birth he had had an enlarged head and delayed developmental milestones. it is probable that he had bilateral haematoma from birth with further bleeding after a fall two weeks before admission. Thick membrane was found bilaterally and could not be completely cleared. However, he showed considerable improvement postoperatively; after one month he was walking and beginning to speak. At 5 years his I.Q. was 74 (Binet). He had secondary optic atrophy with no perception of light in the left eye.

Case 4.-A fourth male child was diagnosed at 18 months. He also had had a large head from birth and retarded developmental milestones. At 1 year he had become tetraplegic after an operation for removal of Meckel's diverticulum. Craniotomy at 18 months showed thick membrane in the right subdural space adherent to the cortex. He remained severely retarded and died at home six months after operation. Necropsy was not performed.

\section{Follow-up}

The length of follow-up varied from one to five years (Table II). Fifteen children (60\%) appeared mentally and physically normal. One child, aged 7 months, died in the immediate post-operative period, and no cause of death was found at necropsy. One (Case 4 above) died six months post-operatively.

TABLE II.-Treatment and Follow-up

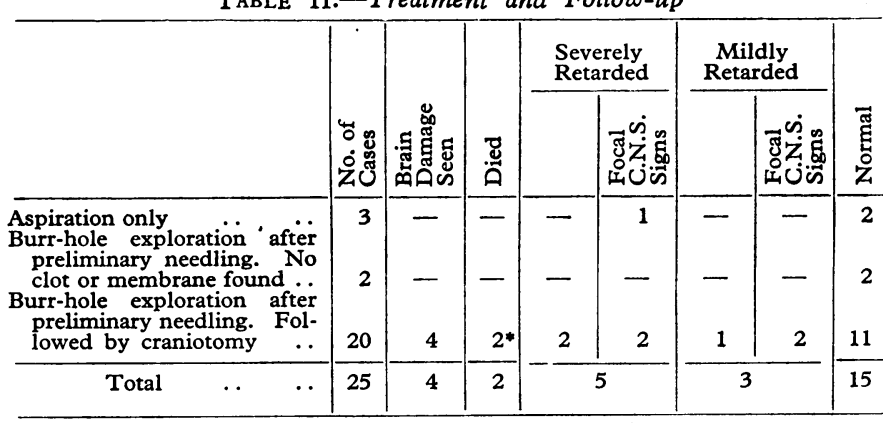

* One in immediate post-operative period; one six months later.

Eight survivors showed varying degrees of mental retardation and physical handicap. Five were severely retarded: three of these are referred to above. In all three cortical damage and adherent membrane were seen at craniotomy. A fourth developed hydrocephalus in association with a basal cyst. The fifth was a neonate treated by needling only; he had moderately severe right hemiparesis, more severe in the arm than in the leg. The two other neonates treated by needling only were developing normally. Three children were mildly retarded. One of these, at the age of 22 months, had solid clot and membranes $1.5 \mathrm{~cm}$. thick removed from the right side at craniotomy; the cortex was depressed but did not appear abnormal. He had a residual left hemiparesis. A second child was operated on at 5 days of age ; on the left side solid clot extended from the frontal to the occipital pole and was $2 \mathrm{~cm}$. thick anteriorly. The cortex appeared normal. He had a mild right hemiparesis and grand-mal attacks. The third, at 4 months of age, had a large hygroma and "flimsy" membranes removed from the left side. The cortex was depressed $1 \mathrm{~cm}$. but appeared normal. He had no localizing signs. No children who were mentally normal had localizing signs in the central nervous system.

\section{Discussion}

In general the cases conform to the usual description of subdural haematoma in infancy. Thus all presented in the first two years of life, the majority in the first six months. Trauma to the head, which characteristically can be slight, is accepted as the most common aetiological factor. The fact that in this series $10(40 \%)$ had no history of birth or post-natal trauma emphasizes that a negative history can never exclude the diagnosis. Sherwood (1930) suggested unadmitted trauma as a possible aetiological factor. Five of the nine cases he described were cared for in institutions or by foster mothers. Ingraham and Matson (1944) and Grunnagle (1949) showed that a high proportion of cases came from a poor socio-economic background. Caffey (1946) reported 23 long-bone fractures in six infants, who all had associated chronic subdural haematoma. The association of subdural haematoma with multiple epiphysial injuries in "the battered baby syndrome" has been drawn attention to again by Griffiths and Moynihan (1963).

Gardner (1932) demonstrated that the membranes formed around the haematoma are semipermeable, and subsequently the increase in the size of the lesion was ascribed to an osmotic effect of the haemolysing red cells. However, Gitlin (1955) demonstrated a high protein content in the subdural fluid relative to the blood serum, and a high ratio of albumin to gamma-globulin and to total protein. He commented that capillary filtrates are normally very low in protein content, so it is difficult to explain the source of the additional albumin on the basis of osmotic pressure alone. He suggests that an effusion occurs through damaged capillary walls. Rabe et al. (1962) demonstrated the passage of serum albumin, labelled with 
radioactive iodine, into the subdural collection of a 5-monthold infant, thus confirming that the source of the protein is the plasma and not significantly local red-cell breakdown. Christensen and Husby (1963), in a histological examination of membranes over 1 month old, showed large abnormal capillaries, especially in the outer membrane and bordering on the fluid interior of the haematoma.

The dominant symptoms and signs accord with other series, and again illustrate that they are nonspecific and common to many diseases of infancy. Convulsions and vomiting were the commonest symptoms reported by Ingraham and Matson (1944), Elvidge and Jackson (1949), and Guthkelch (1953). In two of these series, in contrast to the present one, irritability was a commoner symptom than drowsiness.

Particular attention is drawn to the frequency of retinal haemorrhage, which was present in $64 \%$ of cases. Statten (1948), in a review of 28 cases, found retinal haemorrhage in $80 \%$; Hollenhorst et al. (1957) reported 31 cases, of which $64.5 \%$ had retinal haemorrhage.

Guthkelch (1953) suggests that focal signs may indicate underlying brain damage as subsequently hemiplegia may fail to improve post-operatively. In the present series the repeated pattern of partial third-nerve palsy with contralateral hemiplegia, seen in four cases, perhaps suggests that these focal signs are due to a herniation at the tentorium cerebelli. Fine and Herson (1951) report an acute fatal case which showed impairment of consciousness, right-sided hemiplegia, and incomplete thirdnerve palsy. At necropsy a large left subdural haematoma was found but the brain was normal.

Aspects of the treatment of subdural haematoma in infancy remain controversial. However, it is accepted that initially it is an intracranial space-occupying lesion which if unrelieved may prove fatal. Essentially it causes compression of the surface of the brain without intrinsic damage. Early diagnosis and needling therefore decrease the likelihood of permanent damage to the underlying brain.

Secondly, as connective-tissue membranes form from the inner layer of the dura, and surround the haematoma, there may be a constricting effect upon the growth of the cerebral hemisphere. The necessity to remove these membranes is still debated. Sherwood (1930) reported nine cases treated by needling alone; there were no deaths, but only three children remained mentally normal. He was the first to suggest that removal of the membranes might improve the prognosis. Peet and Kahn (1932) treated nine cases by immediate craniotomy. There were five post-operative deaths but the other four children were normal. Ingraham and Matson (1944) outlined a detailed plan of treatment referred to above, which has since been widely adopted in North America and Great Britain. In 1954 they reported that over 300 infants had been treated and 70-80\% were developing normally for their age. They comment that the most significant factor in prognosis is the extent of cortical atrophy seen at operation. Of the five severely retarded children in the present series four were noted to have cortical damage at operation, while the fifth did not have a craniotomy.

Shulman and Ransohoff (1961) have queried the necessity to remove thin diaphanous membranes. They report 53 children seen in the years 1935-60. Of 20 children in whom membrane was left in situ, $65 \%$ developed normally. Of the entire series $63 \%$ developed normally. However, they comment that heavy inelastic membranes producing signs or symptoms of intracranial pressure or focal cerebral dysfunction must be removed as widely as possible. They, too, suppose that it is the degree to which the underlying brain is able to recover that will determine the prognosis. Ransohoff (1957) drew attention to certain chronic cases with marked enlargement of the skull. In this group the brain may not re-expand to fill the cavity after the removal of the membranes. He prevented reaccumulation of fluid in seven out of eight such cases by subdural pleural shunt. Collins and Pucci (1961) report the clearing of 14 out of 23 haematomas by subdural peritoneal shunts. In these cases serial biopsy of the membrane through burr-holes showed marked regression in thickness, cellularity, and vascularity, provided that drainage was adequate. Collins and Pucci suggest that with adequate drainage excision of membranes is not always indicated.

In the above series early burr-hole exploration, and removal of membranes if present, was carried out in 22 of the 25 cases, so the effect of retained membranes upon the prognosis cannot be judged. There was, however, no instance in which haematoma subsequently reaccumulated.

\section{Conclusions}

Early diagnosis with relief of pressure in the subdural space is probably the most important therapeutic factor in preventing permanent brain damage. Particularly in the neonatal period, subdural needling may be an urgent resuscitative measure when raised intracranial pressure is producing apnoeic attacks. It has been suggested that needling of the fontanelles may produce the condition. The dramatic improvement of symptoms after the initial tap would seem to discount this.

The place of craniotomy and removal of membranes is not as clear. There are opposing views. It is known that the infant's brain doubles in volume in the first three months of life and re-doubles in the next six months. Therefore in the present state of knowledge it would seem politic to remove any possibly constricting membranes. This is particularly so as in skilled hands operative mortality and morbidity has been practically eliminated.

Abnormality of the cortex seen at craniotomy and adherence of membranes to the cortex are associated with a bad prognosis.

\section{Summary}

Twenty-five cases of subdural haematoma in infancy are reviewed. All the patients presented under the age of 2 years, and less than half had a history of trauma. The common presenting symptoms were convulsions, vomiting, and drowsiness; the common signs were increased tension of the anterior fontanelle, retinal haemorrhage, anaemia, and increased head circumference. The non-specificity of the presenting symptoms is stressed. The plan of treatment adopted is outlined, and the prognosis assessed in a follow-up ranging from one to five years. Sixty per cent. of the children appeared physically and mentally normal. Factors affecting the prognosis of this condition and controversial aspects of its treatment are discussed.

I would like to thank Mr. Murray A. Falconer for his help and criticism; and Mr. Peter Schurr, Sir Wilfrid Sheldon, Dr. Eric Stroud, and Dr. Mary Wilmers for permission to study cases under their care.

\section{REFERENCES}

Caffey, J. (1946). Amer. F. Roentgenol., 56, 163.
Christensen, E., and Husby, J. (1963). Acta neurol. scand., 39, 323.

Christensen, E., and Husby, J. (1963). Acta neurol. scand.,

Collins, W. F., and Pucci, G. L. (1961). F. Pediat., 58, 482.

Elvidge, A. R., and Jackson, I. J. (1949). Amer. F. Dis. Child

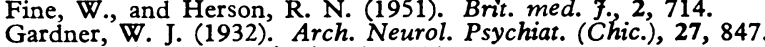

Gitlin, D. (1955). Pediatrics, 16, 345.

Griffiths, D. L., and Moynihan, F. J. (1963). Brit. med. 7., 2, 1558

Grunnagle, J. F. (1949). Penn. med. $\dot{\mathcal{F}}_{\text {., }}$ 52, 729.

Guthkelch, A. N. (1953). Brit. med. 7., 1, 233

Hollenhorst, R. W., Stein, H. A., Keith, H. M., and MacCarty, C. S. (1957), Neurology (Minneap, $7,813$.

Ingraham, F. D., and Matson, D. D. (1944). 7. Pediat. 24, 1.

Ingraham, F. (i954). Neurosurgery of Infancy and Childhood. Thomas, Springfield, Illinois.

Peet, M. M., and Kahn, E. A. (1932). 7. Amer. med. Ass., 98, 1851.

Rabe, E. F., Flynn, R. E., and Dodge, P. R. (1962). Neurology (Minneap.), 12, 79 .

Ransohoff, J. (1957). Pediatrics, 20, 561

Sherwood, D. (1930). Amer. F. Dis. Child., 39, 980.

Shulman, K., and Ransohoff, J. (1961). F.' Neurosurg., 18, 175

Statten, T. (1948). Canad. med. Ass. $\mathcal{F}$., 58, 63. 